\title{
EFFECT OF THE THICKNESS OF INSULATION OF PROTECTED WIRES OF HIGH-VOLTAGE OVERHEAD TRANSMISSION LINES TO THEIR CURRENT CARRYING CAPACITY
}

Introduction. The main direction of technical policy in the design, construction and technical re-equipment of transmission lines is the modernization of electrical networks and increase their energy efficiency in order to increase the throughput and reliability. Problem. Existing calculation methods do not take into account the influence of insulation thickness on the long-term current load of the wires according to the values of the maximum permissible working temperature of the conductors. Purpose. The investigation of the influence of insulation thickness of the protected wires of high-voltage electric transmission lines on their current carrying capacity. Methodology. The long operating temperature of the wire when the rated load current flows is determined based on the heat balance equation. Results. A method has been developed for determining the optimum thickness of polyethylene cross linked and oxide insulation to provide the lowest thermal resistance to the heat transfer of protected wires, the use of which allows increasing the current carrying capacity by $20 \%$ compared to bare wires. It is shown that the internal temperature drop in cross linked polyethylene insulation is an order of magnitude smaller in comparison with the oxide insulation at identical values of the dielectric loss tangent. Originality. The calculations take into account the presence on the surface of a non-insulated aluminum conductor of a natural dense film based on aluminum oxide, which protects it from further contact with air. The capacitance of a single phase conductor with insulation is determined on the basis of the calculation of the electric field in a piecewise homogeneous medium by the method of secondary sources. References 12, tables 3, figures 5 .

Key words: bare conductor, protected wire, cross-linked polyethylene insulation, oxide insulation, thermal resistance, optimal insulation thickness, heat balance, effective heat transfer coefficient, current carrying capacity.

Разработана методика определения оптимальной толщины полиэтиленовой сиитой и оксидной изоляции для обеспечения наименьщего теплового сопротивления теплопередаче защищенных и неизолированных проводов. Обоснована применимость разработанной методики для оптимизации толщины изоляции защищенных проводов напряжением 20 кВ. Показана возможность повыщения пропускной способности по току защищенных проводов на 20 \% по сравнению с неизолированными проводами за счет оптимизации толщины их изоляции. Установлено, что внутренний перепад температуры в сшитой полиэтиленовой изоляции на порядок меньще в сравнении с оксидной изоляции при одинаковых значениях тангенса угла диэлектрических потерь. Библ. 12, табл. 3, рис. 5.

Ключевые слова: неизолированные провода, защищенные провода, сшитая полиэтиленовая изоляция, оксидная изоляция, тепловое сопротивление, оптимальная толщина изоляции, тепловой баланс, эффективный коэффициент теплопередачи, пропускная способность по току.

Introduction. The main direction of the technical policy in the design, construction and technical reequipment of transmission lines (TLs) is the modernization of electric networks and increase of their energy efficiency with the purpose of increasing the capacity and reliability, reducing losses on the basis of an innovative approach to the development and modernization of the existing power transmission complex [1]. Technical re-equipment, reconstruction of electric networks and their development should be carried out on the domestic regulatory framework, taking into account the recommendations of the International Electrotechnical Commission and regional peculiarities regarding the conditions of reliability and environmental safety, taking into account the real cost of land and maximum use of basic materials and equipment of own production.

One of the main directions of work in the construction of high-voltage TLs with increased current carrying capacity is the creation of new types of wires: high-temperature non-insulated ones based on aluminum alloys [2] and protected [3, 4]. The use of hightemperature wires with increased current carrying capacity in two times at an increase in cost, practically by an order of magnitude, is most effectively for highvoltage TLs of $110 \mathrm{kV}$ and above [2].
As a progressive alternative to standard noninsulated aluminum wires for high-voltage TLs of voltage class $6-110 \mathrm{kV}$, it is possible to consider protected wires (PW). The design of a protected wire is a single-stranded multiwire conductor covered with a protective sheath $[3$, 4]. The conductor is made of aluminum alloy, the protective layer is made of light-stabilized cross-linked polyethylene. The permissible long operating temperature of cross-linked polyethylene insulation corresponds to $90{ }^{\circ} \mathrm{C}[3,4]$. The operating temperature of non-insulated aluminum wires does not exceed $75^{\circ} \mathrm{C}[5]$.

The use of PW provides an increase in the current carrying capacity of high-voltage transmission lines in comparison with non-insulated aluminum wires $[3,5]$ (Table 1).

Table 1

Current carrying capacity of aluminum non-insulated and protected wires based on cross-linked polyethylene insulation with thickness of $2.3 \mathrm{~mm}$ of high-voltage TL with voltage of $20 \mathrm{kV}$ (ambient air temperature $25^{\circ} \mathrm{C}$ )

\begin{tabular}{|l|r|r|r|r|r|}
\hline${\text { Strand cross-section } S, \mathrm{~mm}^{2}}^{2}$ & 70 & 120 & 150 & 185 & 240 \\
\hline $\begin{array}{l}\text { Continuous load current of bare wire } \\
\text { I, A }\end{array}$ & 235 & 330 & 370 & 430 & 500 \\
\hline Continuous load current of PW I, A & 310 & 430 & 485 & 560 & 600 \\
\hline
\end{tabular}

(C) G.V. Bezprozvannych, V.M. Zolotaryov, Yu.A. Antonets 
Problem definition. The continuous operating current flowing through the solid conductor is determined on the basis of the thermal calculation [6] and depends on: the active resistance of the strand $R_{g}$, the strand temperature $T_{g}$ and the ambient temperature $T_{c}$, the thermal insulation resistance $R_{t s}$ and the environment (air) resistance $R_{o c}$, the dielectric loss power in insulation $P_{d}=U_{f}^{2} \omega C \operatorname{tg} \delta[7]$

$$
I=\sqrt{\frac{T_{g}-T_{c}-P_{d}\left(R_{t s}+R_{o c}\right)}{R_{g} \cdot\left(R_{t s}+R_{o c}\right)}},
$$

where $U_{f}$ is the phase voltage, $\omega$ is the angular frequency, $C-$ is the own capacitance of wire, $\operatorname{tg} \delta$ is the tangent of the dielectric loss angle of insulation.

Existing calculation methods $[4,7]$ do not take into account the influence of insulation thickness on the continuous current load of the wires by the values of the maximum permissible working temperature of the conductors (strands). The need to analyze the effect of the thickness of cross-linked polyethylene insulation on the long-term permissible working temperature of protected wires is an urgent task, because it allows you to optimize the size of the wire.

The goal of the paper is investigation of the influence of the insulation thickness of the protected wires of high-voltage TLs on their current carrying capacity.

Method for calculating the heat balance. The continuous operating temperature of the wire when the rated load current flows is determined on the basis of the heat balance equation between the extracted $P_{v}$ and the dissipated $P_{\text {otd }}$ power [8]

$$
P_{v}=P_{\text {otd }} \text {. }
$$

The heat extract power is determined by the thermal resistance of the insulation $R_{t s}$, the temperature of the heated strand $T_{g}$ and the surface temperature of the wire $T_{p}[8]$

$$
P_{v}=\frac{T_{g}-T_{p}}{R_{t s}} .
$$

For a wire in the air, the dissipated heat power $P_{\text {otd }}$ depends on the thermal resistance of the ambient air $R_{o c}$ and the surface temperature of the wire $T_{p}$ and the medium temperature $T_{c}[8]$

$$
P_{\text {otd }}=\frac{T_{p}-T_{c}}{R_{t 0}} .
$$

The thermal insulation resistance $R_{t s}$, the thermal resistance of the ambient air $R_{o c}$ and the total thermal resistance $R_{t}$ are defined as [8]

$$
R_{t s}=\frac{1}{2 \lambda} \ln \left(\frac{d_{2}}{d_{21}}\right), \quad R_{t 0}=\frac{1}{\alpha_{e f} S_{t s}}, \quad R_{t}=R_{t s}+R_{t 0},
$$

where $\lambda$ is the insulation heat conductivity; $d_{1}, d_{2}=d_{1}+$ $+2 \Delta_{i n s}, S_{t s}=\pi \cdot d_{2} \cdot l_{p r}$ are the strand diameter, the insulated wire diameter, the insulation thickness and the cooling surface of a wire of length $l_{p r}$, respectively; $\alpha_{e f}=\alpha_{c}+\alpha_{\text {rad }}$ is the effective heat transfer coefficient to the environment due to convection of $\alpha_{c}$ and radiation $\alpha_{\text {rad }}[8,9]$.

Optimum insulation thickness for minimum heat transfer resistance. The calculations take into account the presence on the surface of a non-insulated aluminum conductor of a natural dense film based on aluminum oxide, which protects it from further contact with air. The film thickness is unity - hundreds of nm, depending on the service life and environmental conditions [9].

Fig. 1 shows the dependence of the thermal insulation resistance $R_{t s}$ (curve 1), the heat transfer to the environment $R_{o c}$ (curve 2) and the total thermal resistance $R_{t}$ (curve 3 ) on the ratio of the diameter of the insulated wire $d_{2}$ to the diameter of the aluminum strand $d_{1}$ : $K_{k p}=d_{2} / d_{1}$. For PW with an increase in the thickness of the cross-linked polyethylene insulation $\Delta_{i n s}$ with an unchanged diameter of the strand $d_{1}$, the thermal insulation resistance $R_{t s}$ increases (Fig. 1,a, curve 1 for $\lambda=0.25 \mathrm{~W} / \mathrm{m} \cdot \mathrm{K}$ ), and the thermal resistance $R_{o c}$ of the ambient air decreases (Fig. 1,a: curve 2 for $R_{o c}=$ $=17 \mathrm{~W} / \mathrm{m}^{2} \cdot \mathrm{K}$ ). The total thermal resistance $R_{t}$ (curve 3 ) has a minimum value at the intersection of the curves $R_{t s}$ and $R_{o c}$ corresponding to the critical (optimal) value $K_{k p}$. At $K>K_{k p}$, the thermal resistance to heat transfer increases, at $K<K_{k p}$ - decreases. The critical values of $K_{k p}$ are 1.5 (Fig. 1,a) and 70 (Fig. 1,b) for a protected wire made of cross-linked light-stabilized polyethylene insulation and a wire with oxide insulation, respectively.

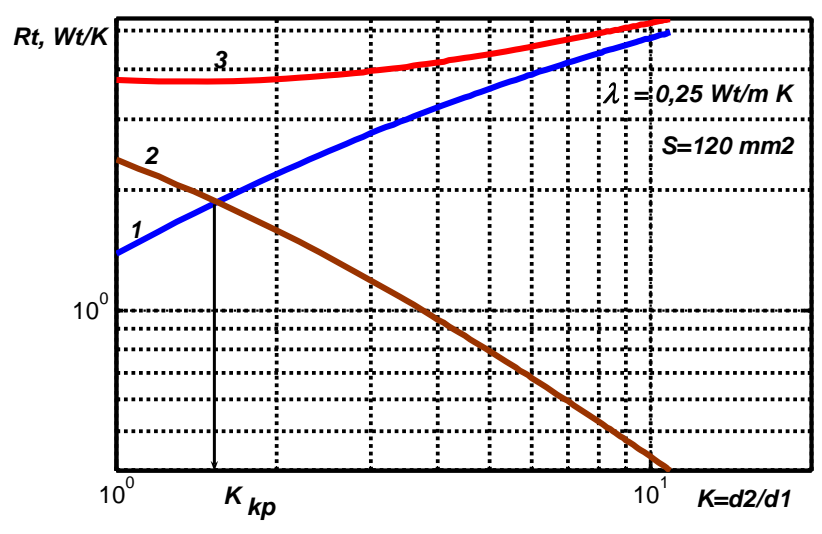

$a$

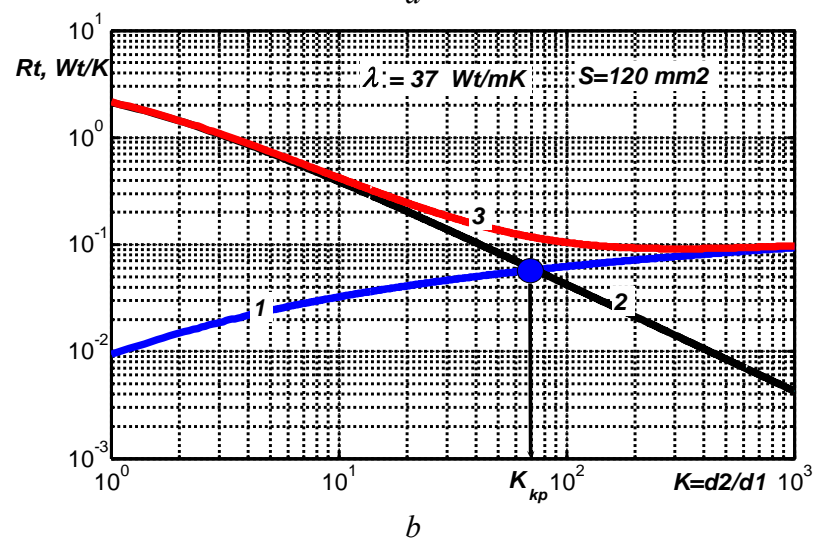

Fig. 1. To the determination of the optimum thickness of insulation of a protected wire and a wire with an oxide dielectric film at the cross-section of the strand $120 \mathrm{~mm}^{2}$

The thickness of the wire insulation, corresponding to the minimum thermal resistance of heat transfer, is optimal. For a protected wire and an oxide-insulated wire, the optimum insulation thickness is $\Delta_{\text {ins opt }}=3.2 \mathrm{~mm}$ and $434 \mathrm{~mm}$, respectively. 
Critical values $K_{k p}$ for $\mathrm{PW}$ at corresponding strand cross-sections are: $K_{k p}=1.9\left(70 \mathrm{~mm}^{2}\right), K_{k p}=1.5\left(120 \mathrm{~mm}^{2}\right)$, $K_{k p}=1.5\left(150 \mathrm{~mm}^{2}\right), K_{k p}=1.4\left(185 \mathrm{~mm}^{2}\right), K_{k p}=1.2\left(240 \mathrm{~mm}^{2}\right)$.

Effect of insulation thickness on the thermal stability of protected wires. On the basis of the presented technique, a thermal calculation has been performed for a continuous current load (see Table 1) of the protected and bare wires of a high-voltage TL with voltage of $20 \mathrm{kV}$ (Table 2). At this stage of the calculation, the dielectric losses power $P_{d}$ in insulation is not taken into account. The effective heat transfer coefficient (Fig. 2) is determined using the criterial equation of natural convection and the Stefan-Boltzmann equation $[8,9]$.

Table 2

Effect of insulation thickness on heat resistance of PW of high-voltage TL with voltage of $20 \mathrm{kV}$

\begin{tabular}{|c|c|c|c|c|}
\hline \multicolumn{5}{|c|}{ Aluminum strand cross-section $S, \mathrm{~mm}^{2}$} \\
\hline 70 & 120 & 150 & 185 & 240 \\
\hline \multicolumn{5}{|c|}{ Continuous current load $I, \mathrm{~A}$} \\
\hline 310 & 430 & 485 & 560 & 600 \\
\hline \multicolumn{5}{|c|}{ 1. Ambient air temperature $25^{\circ} \mathrm{C}$} \\
\hline \multicolumn{5}{|c|}{$\begin{array}{l}\text { 1.1. PW of cross-linked light-stabilized polyethylene } \\
\text { insulation }\end{array}$} \\
\hline \multicolumn{5}{|c|}{$\begin{array}{l}\text { The temperature of the aluminum strand } T_{g},{ }^{\circ} \mathrm{C}: \text { in the } \\
\text { numerator - for the optimal insulation thickness, in the } \\
\text { denominator - by } 33 \% \text { less than the optimal }\end{array}$} \\
\hline $81 / 85$ & $80 / 84$ & $\mathbf{8 0 / 8 2}$ & $80 / 81$ & $75 / 77$ \\
\hline \multicolumn{5}{|c|}{$\begin{array}{l}\text { The temperature of the wire surface } T_{p},{ }^{\circ} \mathrm{C}: \text { in the } \\
\text { numerator - for the optimal insulation thickness, in the } \\
\text { denominator - by } 33 \% \text { less than the optimal }\end{array}$} \\
\hline 75/80 & $\mathbf{7 5 / 8 0}$ & $75 / 77$ & $\mathbf{7 5 / 7 7}$ & $75 / 76$ \\
\hline \multicolumn{5}{|c|}{ 1.2. Bare aluminum wire } \\
\hline \multicolumn{5}{|c|}{$\begin{array}{c}\text { The strand temperature } T_{\mathrm{g}},{ }^{\circ} \mathrm{C}: \text { in the numerator - for bare, } \\
\text { in the denominator - with the oxide film of } \\
\text { thickness of } 100 \mathrm{~nm}\end{array}$} \\
\hline 105/105 & 95/95 & $92 / 92$ & 90/90 & $82 / 82$ \\
\hline \multicolumn{5}{|c|}{ 2. Ambient air temperature $30^{\circ} \mathrm{C}$} \\
\hline \multicolumn{5}{|c|}{$\begin{array}{l}\text { 2.1. PW of cross-linked light-stabilized polyethylene } \\
\text { insulation }\end{array}$} \\
\hline \multicolumn{5}{|c|}{$\begin{array}{l}\text { The temperature of the aluminum strand } T_{g},{ }^{\circ} \mathrm{C} \text { : in the } \\
\text { numerator - for the optimal insulation thickness, in the } \\
\text { denominator - by } 33 \% \text { less than the optimal }\end{array}$} \\
\hline $85 / 90$ & $85 / 85$ & $85 / 85$ & $\mathbf{8 5} / \mathbf{8 7}$ & $77 / 79$ \\
\hline \multicolumn{5}{|c|}{$\begin{array}{l}\text { The temperature of the wire surface } T_{p},{ }^{\circ} \mathrm{C}: \text { in the } \\
\text { numerator - for the optimal insulation thickness, in the } \\
\text { denominator - by } 33 \% \text { less than the optimal }\end{array}$} \\
\hline $80 / 85$ & $80 / 85$ & $80 / 82$ & $80 / 82$ & $76 / 78$ \\
\hline \multicolumn{5}{|c|}{ 2.2. Bare aluminum wire } \\
\hline \multicolumn{5}{|c|}{$\begin{array}{l}\text { The strand temperature } T_{\mathrm{g}},{ }^{\circ} \mathrm{C} \text { : in the numerator - for bare, } \\
\text { in the denominator - with the oxide film of } \\
\text { thickness of } 100 \mathrm{~nm}\end{array}$} \\
\hline $120 / 120$ & $105 / 105$ & $95 / 95$ & 95/95 & $87 / 87$ \\
\hline
\end{tabular}

Fig. 2 shows the results of calculating the effective heat transfer coefficient (Fig. 2,a) and the thermal resistance of the surrounding medium (Fig. 2,b) of a protected and bare wire with different sections of the aluminum strand. An increase in the cooling surface of a protected wire in comparison with a bare wire with identical strand cross-sections leads to a decrease in the effective coefficient of heat transfer and thermal resistance (Fig. 2,a,b): curves 1 and 1' - for a protected wire with a cross-section of $120 \mathrm{~mm}^{2}$ and $150 \mathrm{~mm}^{2}$, 2 and $2^{\prime}$ - for bare wire of cross-section of $120 \mathrm{~mm}^{2}$ and $150 \mathrm{~mm}^{2}$, respectively.

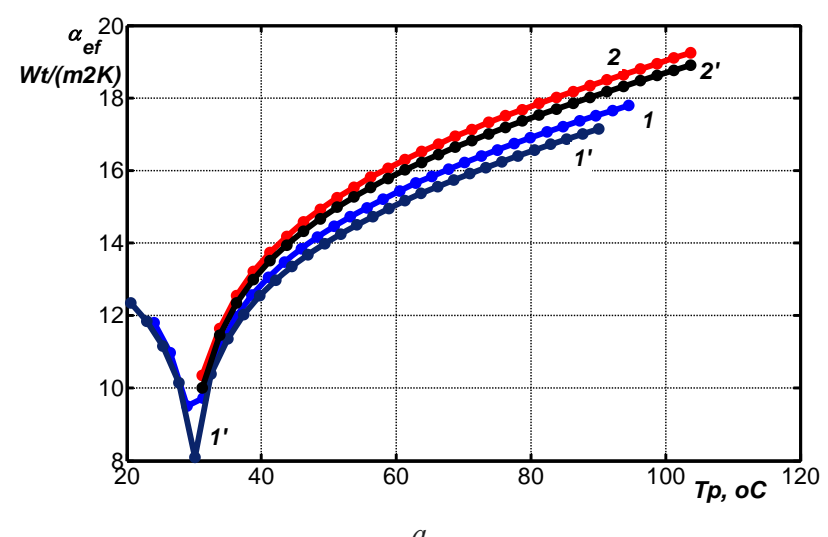

$a$

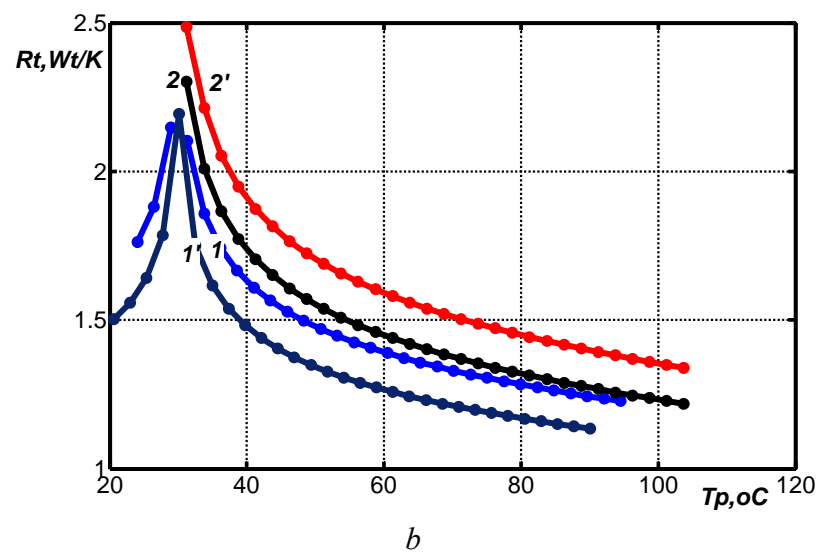

Fig. 2. The effect of the wire cooling surface on the temperature dependencies of the effective heat transfer coefficient $(a)$ and thermal resistance of the environment (air) $(b)$

The results of the thermal calculation show that the protected wires, whose insulation thickness is $33 \%$ less than the optimal one, provide current carrying capacity at an increased ambient temperature of $30^{\circ} \mathrm{C}$ : the strand temperature does not exceed the permissible working temperature of the cross-linked polyethylene insulation (see Table 2, curve 4 of Fig. 3,a).

Reducing the thickness of cross-linked polyethylene insulation makes it possible to reduce the massdimensions of the protected wire.

In Fig. 3, $a$ curve 1 corresponds to the extracted power, curves 2, 3, 4 and 5 - dissipated power: curves 2 and 4 correspond to the optimal insulation thickness, curves $3,5-33 \%$ less than optimal at ambient air temperature of $25^{\circ} \mathrm{C}$ (curves 2, 3) and $30{ }^{\circ} \mathrm{C}$ (curves 4, 5).

The wire temperature $T_{g}$ of bare wires exceeds the permissible working temperature by $30{ }^{\circ} \mathrm{C}-45^{\circ} \mathrm{C}$ (for a $70 \mathrm{~mm}^{2}$ wire) and $7{ }^{\circ} \mathrm{C}-12{ }^{\circ} \mathrm{C}$ (for a $240 \mathrm{~mm}^{2}$ wire) (see Table 2 and Fig. 3,b).

The presence on the bare wire surface of an oxide film of $100 \mathrm{~nm}$ thick does not affect the heat balance 
condition: the temperature on the wire surface remains constant.

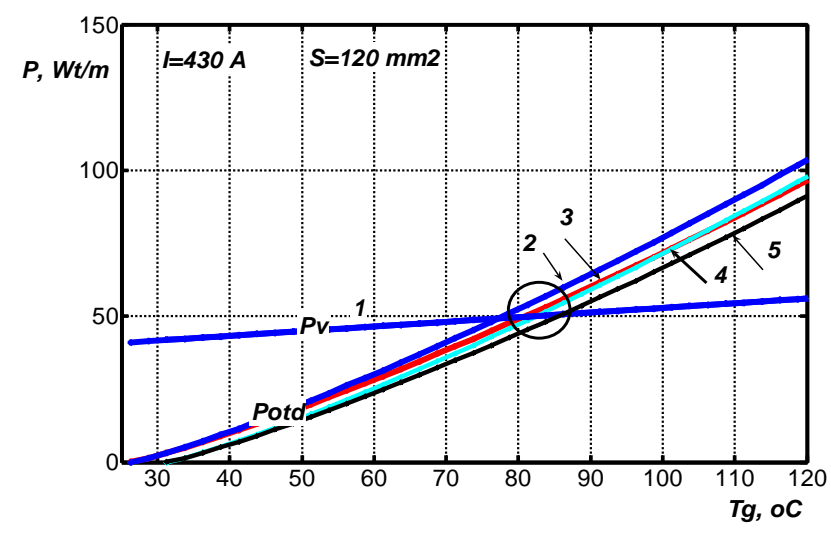

$a$

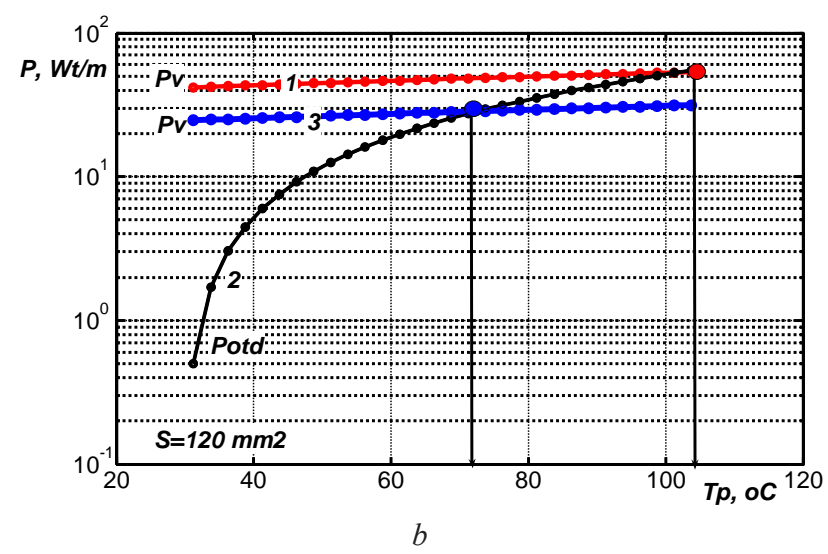

Fig. 3. Heat balance in a protected $(a)$ and bare $(b)$ wire

The requirement to limit the working temperature of bare wires is due to the process of possible annealing of cold-drawn aluminum wires, an increase in plastic elongation and, as a consequence, sagging arrows. At load current of $430 \mathrm{~A}$, the curves of the dissipated $P_{\text {otd }}$ (curve 2) and the extracted power $P_{v}$ (curve 1) intersect at a point corresponding to a temperature of $105{ }^{\circ} \mathrm{C}$ (Fig. 3,b). Reduction of the load current up to $330 \mathrm{~A}$, i.e. by $20 \%$, leads to the intersection of $P_{v}$ (curve 3 ) and $P_{\text {otd }}$ (curve 2) at a point corresponding to a working temperature of $75^{\circ} \mathrm{C}$ (Fig. 3,b).

Effect of dielectric losses in insulation on the current carrying capacity of the protected wire. The internal temperature drop in insulation (see (1)) $\Delta T_{\text {ins }}=$ $=P_{d}\left(R_{t s}+R_{o c}\right)$ is determined by the dielectric losses power $P_{d}=U_{f}^{2} \omega C \operatorname{tg} \delta$, which depends on the electrical characteristics of insulation: the dielectric losses angle tangent and the relative permittivity determining the wire capacity. The capacity of a single phase conductor with insulation is determined on the basis of the calculation of the electric field calculation in a piecewise homogeneous medium by the method of secondary sources [11], which reduces to solving a system of linear algebraic equations (SLAE). The first $\mathrm{Ne}$ rows of SLAE follow from the Fredholm integral equation of the first kind for potentials on the surface of a current-carrying strand (electrode). The following $N d$ rows are from the Fredholm integral equation of the second kind for jumps in the normal component of the field strength $E_{n}$, undergoing a break at the interfaces of dielectric media with relative dielectric permittivities $\varepsilon_{1}$ и $\varepsilon_{2}$ to satisfy the condition: $\varepsilon_{1} \cdot E_{1 n}=$ $=\varepsilon_{2} \cdot E_{2 n}$. The written form of the combined SLAE has the form [12]

$$
\bar{A} \cdot \bar{\sigma}=\bar{U},
$$

where $\bar{\sigma}$ is the matrix-column of unknown calculated densities of secondary charges, $\mathrm{C} / \mathrm{m}^{2} ; \bar{U}$ is the matrixcolumn, the first $\mathrm{Ne}$ elements of which reflect the given potentials of the nodes lying on the electrode, and the remaining ones are equal to zero (the potentials of the nodes lying on the interface of dielectric media); $\bar{A}$ is the square matrix of coefficient.

The total number of nodes (the number of unknown of the charge density) is $N=N e+N d$. Solving SLAE (6) by a numerical method, the calculated density (in vacuum) of secondary charges is determined. The field strength for the electrode surface is determined by the calculated charge density $E_{i}=\sigma_{i} / \varepsilon_{0}$ and for the interfaces of dielectric media $E_{i}=\frac{\sigma_{i}}{2 \varepsilon_{0}}\left(1+\frac{1}{\alpha}\right)$, where $\alpha$ is the parameter related to the permittivity of adjacent media: $\alpha=\left(\varepsilon_{2}-\varepsilon_{1}\right) /\left(\varepsilon_{2}+\varepsilon_{1}\right)$ [12]. The true density $\sigma$ of charges on the surface of the strand, which is insulated by a dielectric with relative dielectric permittivity $\varepsilon_{2}$, is greater by $\varepsilon_{2}$ times [12]. The desired capacitance is defined as the ratio of the true charge to the specified phase voltage. The wires are in the air with dielectric permittivity $\varepsilon_{1}=1$.

Fig. 4 shows the sweep of the electric field strength as a function of the length of the $S D L$ generator $(S D L$ corresponds to the reduction of «sum of DL» - the sum of a plurality of small length sections) for a PW and a $20 \mathrm{kV}$ bare wire with a strand cross-section of $120 \mathrm{~mm}^{2}$. Curve 1 - the optimal thickness of insulation $(3.2 \mathrm{~mm})$ and curve $2-33 \%$ less than the optimal $(2.3 \mathrm{~mm})$ for a protected wire made of cross-linked polyethylene insulation (relative dielectric permittivity $\varepsilon_{2}=2.3$ ). Curve 3 - for a wire with oxide insulation thickness of $100 \mathrm{~nm}$ (relative dielectric permittivity $\varepsilon_{2}=9$ : for a continuous oxide film obtained, for example, by highvoltage oxidation, the value of the relative dielectric permittivity is $\varepsilon=8-10$ at a frequency of $50 \mathrm{~Hz}$ ). Section I - distribution of the field strength along the surface of the strand, section II - along the insulation surface. The relative permittivity greatly influences on the distribution of the electric field strength (compare curves 1, 2 and 3, Fig. 4): the electric field strength on the surface of the wire with the oxide film is $30 \%$ higher in comparison with the PW with the cross-linked polyethylene insulation.

Table 3 shows the results of calculating the intrinsic capacitance of the wires for different sections and the thickness of the insulation. 
The results of the calculations show (Fig. 5) that adjacent phase protective wires located by a triangular at a distance of $50 \mathrm{~cm}$ from each other lead to a decrease in the intrinsic capacity of the wires: $18 \%$ for the wire at the apex of the triangle $\left(C_{1}=9.7 \mathrm{pF} / \mathrm{m}\right) ; 8 \%$ for two other $\left(C_{2}=10.6 \mathrm{pF} / \mathrm{m}\right.$ and $\left.C_{3}=10.6 \mathrm{pF} / \mathrm{m}\right)$.

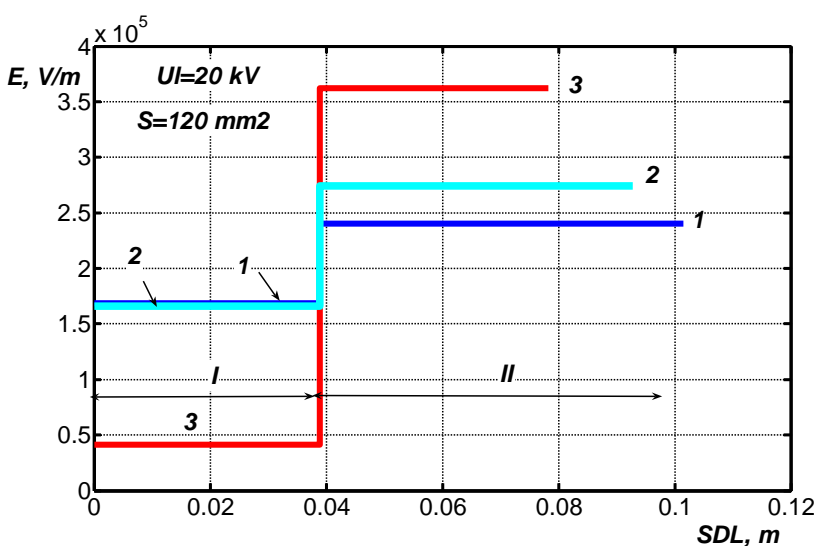

Fig. 4. The effect of the relative dielectric permittivity and insulation thickness on the distribution of the electric field strength over the wire surface

Table 3

Effect of insulation thickness on intrinsic capacitance of wires of high-voltage TL of voltage of $20 \mathrm{kV}$

\begin{tabular}{|c|c|c|c|c|}
\hline \multicolumn{5}{|c|}{ Aluminum strand cross-section $S, \mathrm{~mm}^{2}$} \\
\hline 70 & 120 & 150 & 185 & 240 \\
\hline \multicolumn{5}{|c|}{$\begin{array}{l}\text { 1. Protected wire capacitance } \boldsymbol{C}, \mathbf{p F} / \mathbf{m} \\
\text { optimal insulation thickness }\end{array}$} \\
\hline 11.1 & 11.5 & 11.7 & 11.9 & 12.1 \\
\hline \multicolumn{5}{|c|}{ insulation thickness by $33 \%$ less than the optimal } \\
\hline 10.9 & 11.4 & 11.5 & 11.7 & 12.0 \\
\hline \multicolumn{5}{|c|}{$\begin{array}{l}\text { 2. Wire capacitance } \boldsymbol{C}, \mathbf{p F} / \mathbf{m} \\
\text { xide insulation thickness } 100 \mathrm{~nm}\end{array}$} \\
\hline 10.5 & 11.0 & 11.3 & 11.5 & 11.8 \\
\hline
\end{tabular}

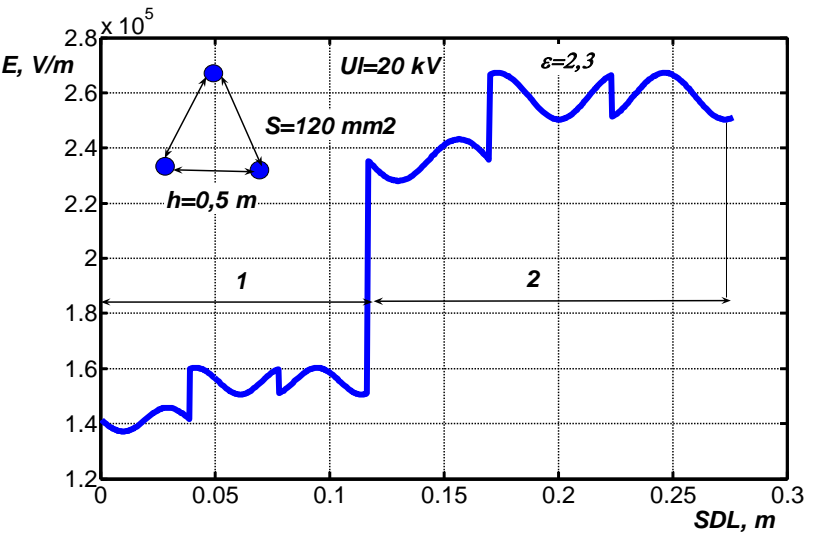

Fig. 5. The effect of near located protected wires on the distribution of the electric field strength along the surfaces of the strands (curve 1) and cross-linked polyethylene insulation (curve 2)

The dielectric losses power in XLPE insulation is $0.5 \cdot 10^{-3} \mathrm{~W} / \mathrm{m}, 0.005 \mathrm{~W} / \mathrm{m}$ for $\operatorname{tg} \delta=0.1 \%$ and $1 \%$, respectively. The thermal resistance of the wire is $1 \mathrm{~m} \cdot{ }^{\circ} \mathrm{C} / \mathrm{W}$ at core temperature of $90{ }^{\circ} \mathrm{C}$ and ambient air temperature of $30{ }^{\circ} \mathrm{C}$ (see Fig. 2,b). The internal temperature drop in the insulation $\Delta T_{i n s}=P_{d}\left(R_{t s}+R_{o c}\right)$ (see formula (1)) is $0.12 \%$ and $1.2 \%$ for the corresponding values of $\operatorname{tg} \delta$ in comparison with the total temperature difference between the strand and ambient air $\Delta T=T_{g}-T_{c}$. For wire with oxide insulation $\Delta T_{i n s}=10 \%$ $(\operatorname{tg} \delta=1 \%$ ), which causes a reduction in the permissible current load in the bare wire.

\section{Conclusions.}

1. For the first time, a method has been developed for determining the optimum thickness of polyethylene crosslinked and oxide insulation to provide the lowest thermal resistance to the heat transfer of protected wires, the use of which makes it possible to increase the current carrying capacity by $20 \%$ compared to bare wires.

2. The applicability of the developed technique for optimizing the thickness of insulation, both separated protected wires of various types, and for high-voltage transmission lines based on them, is justified, provided that the minimum distance between phase wires of the transmission line is limited to $0.5 \mathrm{~m}$.

3. The results of the studies performed, provided they are appropriately experimentally substantiated, can become the scientific basis for the creation of a new class of compact high-voltage transmission lines with increased current carrying capacity.

\section{REFERENCES}

1. Enterprise standard. Technical policy of $S E$ «NEK» UKRENERGO» in the field of development and operation of in trunk and interstate electric networks. SOU NEC 20.261. Kyiv, 2017. 84 p. (Ukr).

2. Catalog of LLC «Sim-Ross-Lamifil》. Energy-efficient wires of a new generation for power lines. 2014. 26 p. (Rus).

3. DSTU 4743: 2007. Provody samoutrymni izolovani ta zakhyshcheni dlia povitrianykh linii elektroperedavannia. Zahalni tekhnichni umovy [State Standard of Ukraine DSTU 4743: 2007. Wires self-supporting insulated and protected for overhead transmission lines. General specifications]. Kyiv, 2007. 26 p. (Ukr).

4. Shcherba A.A., Peretyatko Yu.V., Zolotaryov V.V. Samonesushchie izolirovannye $i$ vysokovol'tnye zashchishchennye provoda [Self-supporting insulated and highvoltage protected wires]. Institute of Electrodynamics of the NAS of Ukraine, National Technical University of Ukraine «KPI», Private Joint-stock company Yuzhcable works Publ., 2008. 271 p. (Rus).

5. Guide for qualifying high temperature conductors for use on overhead transmission lines. CIGRÉ TB 426. 2010. 44 p.

6. IEC 60287-1-1:2006 Electric cables - Calculation of the current rating - Part 1-1: Current rating equations (100\% load factor) and calculation of losses. General specifications.

7. Bezprozvannych G.V., Naboka B.G., Moskvitin E.S. Substantiation of electrophysical characteristics of high-voltage power cable semiconducting screens with stitched insulation. Electrical engineering \& electromechanics, 2010, no.3, pp. 4447. (Rus). doi: 10.20998/2074-272X.2010.3.10.

8. Bezprozvannych G.V., Naboka B.G. Matematicheskie modeli $i$ metody rascheta elektroizoliatsionnykh konstruktsii [Mathematical models and methods of calculation of electrical designs]. Kharkiv, NTU «KhPI» Publ., 2012. 108 p. (Rus). 
9. Carslaw H.S., Jaeger J.C. Conduction of heat in solids. Second Ed. Clarendon Press, London, 2003. 510 p.

10. Hunter M., Fowle P. Natural and thermally formed oxide films on aluminium. Journal of the Electrochemical Society, 1956, vol.103, no.9, pp. 482-485. doi: 10.1149/1.2430389.

11. Naboka B.G. Raschety elektrostaticheskikh polei $v$ elektroizoliatsionnoi tekhnike: uchebnoe posobie dlia studentov elektroenergeticheskikh spetsial'nostei [Settlements electrostatic fields in the insulating technique: a textbook for students of electric power specialties]. Kiev, IEDL Publ., 1995. 120 p. (Rus). 12. Bezprozvannych A.V. High electric field and partial discharges in bundled cables. Technical electrodynamics, 2010, no.1, pp. 23-29. (Rus).

Received 25.01.2018
G.V. Bezprozvannych ${ }^{1}$, Doctor of Technical Science, Professor, V.M. Zolotaryov ${ }^{2}$, Doctor of Technical Science, Professor,

Yu.A. Antonets ${ }^{2}$, Candidate of Technical Science,

${ }^{1}$ National Technical University «Kharkiv Polytechnic Institute», 2, Kyrpychova Str., Kharkiv, 61002, Ukraine, phone +380 57 7076010,

e-mail: bezprozvannych@kpi.kharkov.ua

${ }^{2}$ Private Joint-stock company Yuzhcable works,

7, Avtogennaya Str., Kharkiv, 61099, Ukraine, phone +380 577545312 ,

e-mail: zavod@yuzhcable.com.ua, antonets@yuzhcable.com.ua

How to cite this article:

Bezprozvannych G.V., Zolotaryov V.M., Antonets Yu.A. Effect of the thickness of insulation of protected wires of high-voltage overhead transmission lines to their current carrying capacity. Electrical engineering \& electromechanics, 2018, no.2, pp. 41-46. doi: 10.20998/2074-272X.2018.2.07. 